\title{
Vetiver-polypropylene composites: Physical and mechanical properties
}

\author{
Yupaporn Ruksakulpiwat *, Nitinat Suppakarn, Wimonlak Sutapun, Wandee Thomthong
}

School of Polymer Engineering, Institute of Polymer Engineering, Suranaree University of Technology, Nakhon Ratchasima 30000, Thailand

Received 10 May 2005; received in revised form 25 January 2006; accepted 14 February 2006

\begin{abstract}
Injection molded vetiver-polypropylene (PP) composites at various ratios of vetiver content and vetiver length were prepared. When compared to PP, vetiver-PP composites exhibited higher tensile strength and Young's modulus but lower elongation at break and impact strength. An increase in vetiver content led to an increase in viscosity, heat distortion temperature, crystallization temperature, and Young's modulus of the composites. On the other hand, the decomposition temperature, tensile strength, elongation at break, and impact strength decreased with increasing vetiver content. The chemical treatment of the vetiver grass improved the mechanical properties of the composites.
\end{abstract}

(C) 2006 Elsevier Ltd. All rights reserved.

Keywords: A. Fibres; A. Polymer-matrix composites (PMCs); B. Physical properties; B. Mechanical properties

\section{Introduction}

In recent year, natural fibers have been increasingly used as alternative fillers in many areas of polymer composites [1-3]. Their advantages over synthetic fibers are low cost, less tool wear during processing, low density, environmental friendly and biodegradability [4-6]. Examples of the natural fibers which have already been used in polymer composite industry are jute, flax and sisal fibers. Vetiver grass is one of the interesting candidates. Vetiver grass is a tropical plant which well adapt to different environment conditions. In Thailand, it is found growing in a wide range of areas. The dominant vetiver grass species grown in Thailand is Vetiveria Zizanioides. According to His Majesty the King Bhumipol Aduljadej of Thailand's Royal Initiation the main purpose of vetiver grass cultivation is to conserve soil and water, particularly for the steep slope areas. In spite of the effort, some farmers are still reluctant to accept its valuable attributes because cultivation of vetiver in agricultural areas in order to conserve soil and water does not produce tangible benefits in terms of revenue. Actually,

\footnotetext{
${ }^{*}$ Corresponding author. Tel.: +66 442244 33; fax: +66 44224431.

E-mail address: yupa@ccs.sut.ac.th (Y. Ruksakulpiwat).
}

vetiver leaves and roots have to be cut to keep the vetiver rows in order [7]. This becomes an inspiration of this work to make use of the vetiver grass as a filler in polymer composites which can help the farmer gain some extra income. The use of PP as a polymer matrix for short fiber reinforced composite is due to its high cost-performance ratio and its low processing temperature, which is essential because of the relatively low thermal stability of natural fibers.

\section{Experimental procedures}

\subsection{Materials}

A commercial grade of isotactic PP (700J) with a density of $0.910 \mathrm{~g} / \mathrm{cm}^{3}$ was supplied by Thai Polypropylene Co., Ltd. Vetiver grass (Vetiveria Zizanioides) was obtained from The Land Development Department, Nakhon Ratchasima, Thailand. In this research, vetiver leaves with length of $30 \mathrm{~cm}$ from vetiver culm were used. The ages of vetiver grass are around 6-8 months. Sodium hydroxide $(\mathrm{NaOH})$, laboratory grade, obtained from Merck and vinyltrimethoxy silane (A-171) coupling agent obtained from Optimal Tech Co., Ltd were used. 


\subsection{Sample preparations}

\subsubsection{Vetiver grass preparations}

Vetiver grass was prepared as vetiver leaves (VL), $\mathrm{NaOH}$ treated vetiver leaves $(\mathrm{NaOH}-\mathrm{VL})$, vetiver fibers $(\mathrm{VF})$ and $\mathrm{NaOH}$-silane treated vetiver fiber $(\mathrm{NaOH}$-silane-VF). First, vetiver grass was washed by water to get rid of dirt and dried by sunlight for one day. To prepare VL, the washed vetiver leaves were ground by a Retsch grinder machine and sieved into the length of $2 \mathrm{~mm}$. To prepare $\mathrm{NaOH}-$ $\mathrm{VL}$, the washed vetiver leaves were immersed in $1 \%(\mathrm{w} / \mathrm{v})$ sodium hydroxide solution for five days, washed by water and then ground by a Retsch grinder machine. The $\mathrm{NaOH}-$ $\mathrm{VL}$ was prepared into three different lengths; $0.1 \mathrm{~mm}$, $2 \mathrm{~mm}$, and $4 \mathrm{~mm}$. The average length of $\mathrm{NaOH}-\mathrm{VL}$ was measured by using a Nikon polarized optical microscope (model Eclipes E600 POL). The average lengths of $\mathrm{NaOH}-\mathrm{VL}$ were calculated based on 100 samples.

To prepare VF, the washed vetiver leaves were immersed in $1 \%(\mathrm{w} / \mathrm{v})$ sodium hydroxide solution for five days, washed by water and then brushed. Then, VF were chopped into the length of $2 \mathrm{~mm}$. To prepare $\mathrm{NaOH}$-silane-VF, vetiver fibers were immersed in $5 \%(\mathrm{w} / \mathrm{v})$ sodium hydroxide solution for $4 \mathrm{~h}$ then they were washed by water and dried in an oven at $80^{\circ} \mathrm{C}$ for $6 \mathrm{~h}$. Then the dried fibers were immersed in $2 \%(\mathrm{w} / \mathrm{v})$ silane solution $(\mathrm{pH}=3.5)$ for $1 \mathrm{~h}$ and washed by water. VL, NaOH-VL, VF and $\mathrm{NaOH}-$ silane-VF were dried in an oven at $80{ }^{\circ} \mathrm{C}$ for $6 \mathrm{~h}$ before use.

\subsection{Vetiver-PP composites preparations}

Vetiver grass and PP were mixed in an internal mixer (model Hakke Rheomix Polylab) at $170{ }^{\circ} \mathrm{C}$ with a rotor speed of $50 \mathrm{rpm}$. Two different mixing procedures, method $\mathrm{A}$ and method $\mathrm{B}$, were used to prepare the composites.

\subsubsection{Method A}

Vetiver grass was added after melting PP for $5 \mathrm{~min}$ in an internal mixer and the mixing time after adding vetiver grass was $5 \mathrm{~min}$. This method was used to prepare $20 \%$ vetiver-PP composites at various vetiver lengths.

\subsubsection{Method B}

Vetiver grass and PP were mixed together for $10 \mathrm{~min}$ in an internal mixer. This method was used to prepare the composites with $2 \mathrm{~mm}$. vetiver length at various vetiver contents.

A Chuan Lih Fa injection machine (model CLF 80P) was used to prepare the composite specimens with a melt temperature of $170{ }^{\circ} \mathrm{C}$, a mold temperature of $25^{\circ} \mathrm{C}$, an injection speed of $46 \mathrm{~cm}^{3} / \mathrm{s}$, an injection pressure of $960 \mathrm{~kg} /$ $\mathrm{cm}^{2}$, and a holding pressure of $640 \mathrm{~kg} / \mathrm{cm}^{2}$.

\subsection{Vetiver grass characterizations}

The density of VF was determined using a specific gravity bottle (pycnometer) with $p$-xylene as the fluid. The diameter of VF was measured using a Nikon polarizing optical microscope (model Eclipes E600 POL). Tensile properties of VF were examined using an Instron universal testing machine (model 4502) with a crosshead speed of $120 \mathrm{~mm} / \mathrm{min}$ and a gauge length of $100 \mathrm{~mm}$. The chemical compositions of VL, NaOH-VL, and VF were obtained from X-Ray Fluorescence Spectrometer (model ED 2000). Thermal decomposition patterns of $\mathrm{VL}, \mathrm{NaOH}-\mathrm{VL}$, and VF were obtained from a TA thermogravimetric analyzer (model SDT 2960). Each sample was heated at a heating rate of $10{ }^{\circ} \mathrm{C} / \mathrm{min}$ from $30-600{ }^{\circ} \mathrm{C}$ under a nitrogen atmosphere and switched over to an oxygen atmosphere from $600-800{ }^{\circ} \mathrm{C}$. The surface morphology of vetiver grass was examined using a scanning electron microscope (model JSM 6400).

\subsection{Vetiver-PP composite characterizations}

\subsubsection{Thermal properties}

Thermal decomposition patterns of vetiver-PP composites obtained from injection molding were determined using a TA thermogravimetric analyzer (model SDT 2960). Each composite sample was heated at a heating rate of $10^{\circ} \mathrm{C} /$ min from $30-600{ }^{\circ} \mathrm{C}$ under a nitrogen atmosphere and switched over to an oxygen atmosphere from $600-800{ }^{\circ} \mathrm{C}$.

Crystallization temperature of vetiver-PP composites were investigated using a Perkin Elmer differential scanning calorimeter (model DSC-7). The test procedure for each composite was performed in three steps under a nitrogen atmosphere. First, the first heating scan was performed by heating a composite sample from $25^{\circ} \mathrm{C}$ to $200{ }^{\circ} \mathrm{C}$ at a heating rate of $10^{\circ} \mathrm{C}$, and annealing for $5 \mathrm{~min}$ to remove the thermal history. Second, the cooling scan was begun by cooling the sample to $25^{\circ} \mathrm{C}$ at a cooling rate of $10^{\circ} \mathrm{C} /$ $\mathrm{min}$. Finally, the second heating scan was done by heating the sample from $25^{\circ} \mathrm{C}$ to $200{ }^{\circ} \mathrm{C}$ at a heating rate of $10^{\circ} \mathrm{C} /$ min under a nitrogen atmosphere. The crystallinity of vetiver-PP composites was calculated using the following equation:

$$
\begin{aligned}
\% \text { Crystallinity }= & \left(\Delta \mathrm{H}_{\text {sample }} / \Delta \mathrm{H}_{100 \% \text { crystalline }}\right) \\
& \times(1 /(1-\mathrm{wt}(\text { fiber }))) \times 100
\end{aligned}
$$

where $\Delta \mathrm{H}_{\text {sample }}$ is the heat of fusion of sample obtained from the first heating scan $(\mathrm{J} / \mathrm{g}), \Delta \mathrm{H}_{100 \% \text { crystalline is the heat }}$ of fusion of pure crystalline. In case of PP, $\Delta \mathrm{H}_{100 \% \text { crystalline }}$ is $207.1 \mathrm{~J} / \mathrm{g}$ [8] and wt(fiber) is the weight fraction of vetiver grass in the composite.

\subsubsection{Rheological properties}

Melt flow index (MFI) of vetiver-PP composites was obtained using a Kayeness melt flow indexer (model 4004 ) at $170{ }^{\circ} \mathrm{C}$ with a load cell of $2.160 \mathrm{~kg}$ and melt time of $360 \mathrm{~s}$.

Shear viscosity at various shear rates of vetiver-PP composites was measured using a Kayeness capillary rheometer (model D5052m) at $170{ }^{\circ} \mathrm{C}$. 


\subsubsection{Mechanical properties}

Tensile properties of vetiver-PP composites were examined using an Instron universal testing machine (model 5565 ) with a load cell of $5 \mathrm{kN}$, a crosshead speed of $10 \mathrm{~mm} / \mathrm{min}$ and a gauge length of $80 \mathrm{~mm}$. The tensile strength of PP was obtained using a test speed of $50 \mathrm{~mm} /$ $\mathrm{min}$. This is because PP specimen does not break at a speed of $10 \mathrm{~mm} / \mathrm{min}$. Izod impact strength of unnotched composites were examined using an Atlas impact testing machine (model BPI).

Heat distortion temperature (HDT) of vetiver-PP composites was investigated using a HDT testing machine (model HDV 1) at a heating rate of $120^{\circ} \mathrm{C} / \mathrm{h}$ using a load cell of $455 \mathrm{kPa}$.

\subsubsection{Morphological properties}

The surface morphology of a fracture surface of composite specimens was investigated using a scanning electron microscope (model JSM 6400).

\subsubsection{Weathering resistance}

The degradation of vetiver-PP composites was accelerated in an artificial environmental condition using a Xenon Weather-Ometer (model S3000) from Atlas electric devices company. The test condition is set to a temperature of $65 \pm 4{ }^{\circ} \mathrm{C}$, irradiation intensity of Xenon lamp at $0.70 \mathrm{~W} /$ $\mathrm{m}^{2}$, relative humidity of $70 \%$, spray cycle at the rate of $2 \mathrm{~min} / \mathrm{h}$, and total exposure time of 10 days. This set condition approximately equals to the average temperature of $27.7^{\circ} \mathrm{C}$, relative humidity of $70.2 \%$, rainfall at $90.3 \mathrm{~mm}$. and total solar radiation at $6898.5 \mathrm{MJ} / \mathrm{m}^{2}$ which is the natural environment in Nakhon Ratchasima region.

\section{Results and discussion}

\subsection{Physical and mechanical properties of vetiver grass}

The physical and mechanical properties of VF are shown in Table 1 . The density of VF is in the same range as flax. The tensile strength of $\mathrm{VF}$ are in the same range with those of jute flax and sisal but higher than that of coir fiber. Young's modulus of VF and jute are in the same range which is higher than those of sisal and coir but lower than those of jute and flax. Elongation at break of VF is higher than that of jute fiber but lower than those of flax, sisal and coir.
Table 2

Chemical compositions of VL, NaOH-VL, and VF obtained from X-ray fluorescence spectrometer

\begin{tabular}{lclc}
\hline Chemical compositions & VL (wt.\%) & NaOH-VL (wt.\%) & VF (wt.\%) \\
\hline $\mathrm{C}$ & 89.39 & 97.30 & 99.00 \\
$\mathrm{SiO}_{2}$ & 5.74 & 1.17 & 0.34 \\
$\mathrm{~K}_{2} \mathrm{O}$ & 3.34 & 0.21 & 0.02 \\
$\mathrm{P}_{2} \mathrm{O}_{5}$ & 0.33 & 0.12 & 0.03 \\
$\mathrm{SO}_{3}$ & 0.28 & 0.05 & 0.02 \\
$\mathrm{Al}_{2} \mathrm{O}_{3}$ & 0.14 & 0.05 & 0.02 \\
$\mathrm{MgO}$ & 0.07 & 0.07 & 0.07 \\
$\mathrm{Cl}$ & 0.07 & 0.02 & 0.01 \\
$\mathrm{MnO}$ & 0.05 & 0.04 & 0.02 \\
$\mathrm{Na}_{2} \mathrm{O}$ & 0.00 & 0.01 & 0.00 \\
Others & 0.10 & 0.07 & 0.01 \\
\hline
\end{tabular}

The chemical compositions of VL, NaOH-VL, and VF obtained from X-ray fluorescence spectrometer are shown in Table 2. They compose of both organic and inorganic constituents. The highest amount of inorganic composition is $\mathrm{SiO}_{2}$. In addition, $\mathrm{VL}$ shows the highest amount of $\mathrm{SiO}_{2}$ compared to $\mathrm{NaOH}-\mathrm{VL}$ and VF.

\subsection{Thermal properties of vetiver grass and vetiver-PP composites}

\subsubsection{The effect of chemical treatment on thermal properties of vetiver grass}

TGA and DTG curves of VL, NaOH-VL, VF, and $\mathrm{NaOH}$-silane-VF are shown in Fig. 1. All TGA curves show the initial transition around $100{ }^{\circ} \mathrm{C}$ due to the moisture evaporation. The moisture content is about $3 \%$. The decomposition temperature of $\mathrm{VL}$ around $174{ }^{\circ} \mathrm{C}$ may be caused by the loss of low molecular weight components such as wax. In case of $\mathrm{NaOH}-\mathrm{VL}, \mathrm{VF}$, and $\mathrm{NaOH}$-silane-VF, the decomposition of the low molecular weight components is not observed. This indicates that the low molecular weight components are removed from vetiver leaves by $\mathrm{NaOH}$ treatment. The hemicellulose decomposition temperature of $\mathrm{VL}, \mathrm{NaOH}-\mathrm{VL}, \mathrm{VF}$, and $\mathrm{NaOH}$-silane- $\mathrm{VF}$ are not significantly different, i.e. around $310^{\circ} \mathrm{C}$. In addition, the decomposition temperatures of $\alpha$-cellulose of $\mathrm{NaOH}-\mathrm{VL}, \mathrm{VF}$, and $\mathrm{NaOH}$-silane-VF are around $348^{\circ} \mathrm{C}, 346^{\circ} \mathrm{C}$, and $343^{\circ} \mathrm{C}$, respectively. In case of $\mathrm{VL}$, the decomposition temperature of $\alpha$-cellulose cannot be observed as a peak in DTG curves. However, the beginning of $\alpha$-cellulose decomposition temperature of VL can be observed around $333^{\circ} \mathrm{C}$ from DTG

Table 1

The physical and mechanical properties of VF and other natural fibers

\begin{tabular}{lllll}
\hline Properties & VF & Jute $^{(1)}$ & Flax $^{(1)}$ & Sisal $^{(1)}$ \\
\hline Density $\left(\mathrm{g} / \mathrm{cm}^{3}\right)$ & 1.5 & $1.3-1.4$ & 1.5 & 1.4 \\
Diameter $(\mu \mathrm{m})$ & $100-220$ & $25-200$ & - & $50-200$ \\
Tensile strength $(\mathrm{MPa})$ & $247-723$ & $393-773$ & $345-1100$ & $468-640$ \\
Young's modulus $(\mathrm{GPa})$ & $12.0-49.8$ & $13.0-26.5$ & 27.6 & $9.4-22.0$ \\
Elongation at break $(\%)$ & $1.6-2.4$ & $1.1-1.5$ & $2.7-3.2$ & $3.0-7.0$ \\
\hline
\end{tabular}




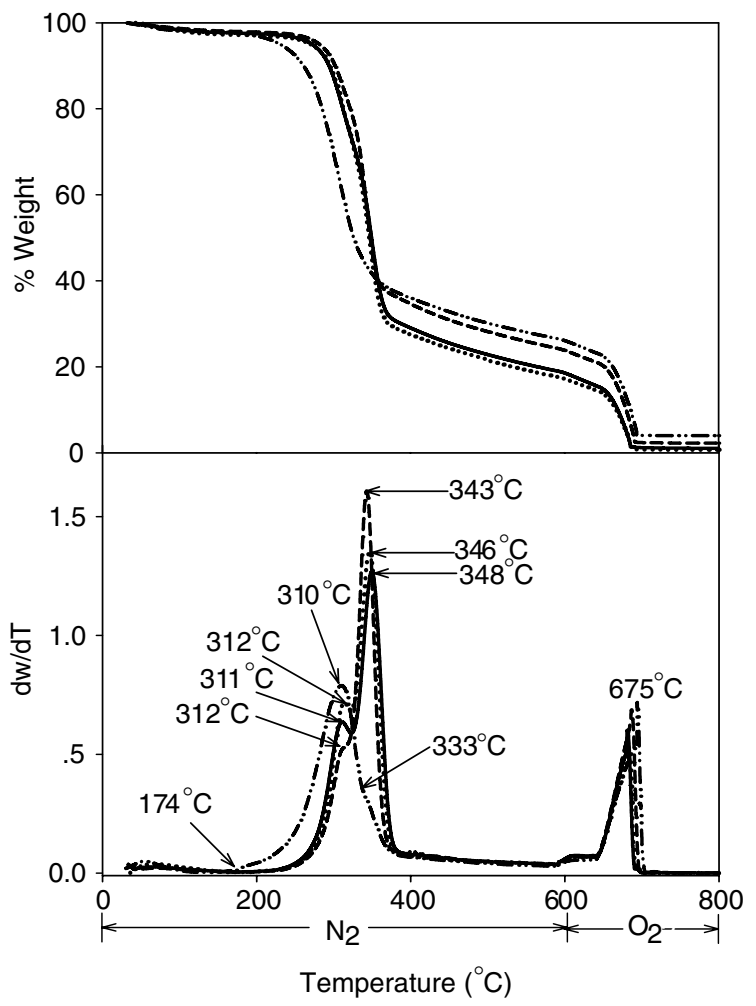

Fig. 1. TGA and DTG curves of VL, NaOH-VL, VF, and NaOH-silaneVF.

curves. The decomposition temperatures of hemicellulose and $\alpha$-cellulose of vetiver grass are in the same range as those of jute, hemp, and sisal [9-11]. The decomposition temperature of carbon residue from the oxidation of organic components in vetiver grass can be observed around $675^{\circ} \mathrm{C}$. The residue weight of VL left around $800^{\circ} \mathrm{C}$ is higher than that of $\mathrm{NaOH}-\mathrm{VL}, \mathrm{VF}$, and $\mathrm{NaOH}$-silane-VF. This may be due to inorganic components in the grass, especially silica as shown in Table 2 .

\subsubsection{The effect of vetiver content on thermal properties of vetiver-PP composites}

TGA and DTG curves of PP and VF-PP composites at various vetiver contents are shown in Fig. 2. At higher vetiver content, the higher amount of moisture is observed. The decomposition temperature of $\mathrm{PP}$ is at $445^{\circ} \mathrm{C}$ and PP completely decomposes around $500{ }^{\circ} \mathrm{C}$. The decomposition temperatures of hemicellulose $\left(308-310^{\circ} \mathrm{C}\right)$ and $\alpha$-cellulose $\left(352-353^{\circ} \mathrm{C}\right)$ are observed when the vetiver content is increased from $10 \%$ to $20 \%$ and $30 \%$. The decomposition temperature of $\alpha$-cellulose of the composite is higher than that of VF. This is because the surrounding PP matrix retards the decomposition of $\alpha$-cellulose. With decreasing PP content, the beginning of decomposition of the composites decreases due to the low thermal stability of vetiver grass.

DSC curves of the PP and VF-PP composites at various vetiver contents obtained from the first heating scan, the cooling scan, and the second heating scan are shown

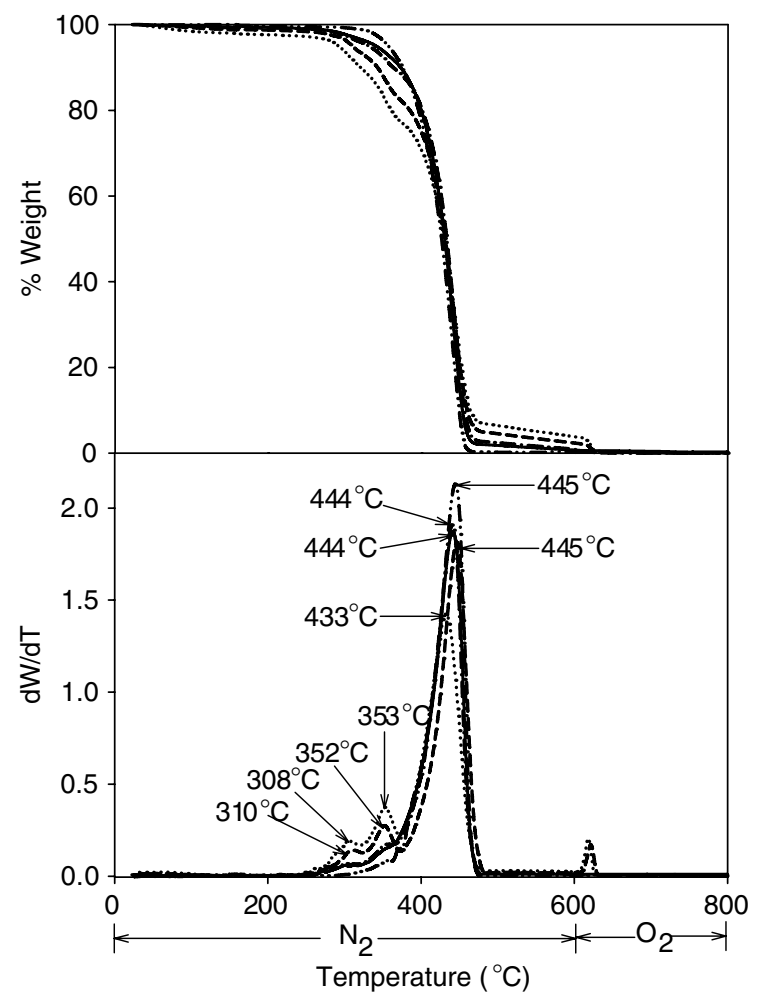

Fig. 2. TGA and DTG curves of PP and VF-PP composites at 5\%,10\%, $20 \%$, and $30 \%$ vetiver contents.

in Fig. 3(a)-(c), respectively. The first heating curve of PP shows a single melting peak while those of VF-PP composites show two small melting peaks. These two small peaks are possibly attributed to different forms of PP crystal formed during processing [12]. These different forms of crystal disappear after removing the thermal history as shown by the narrow melting peak in the second heating curve. From the second heating curves the melting temperature of VF-PP composites at various vetiver contents shows no difference. This is similar to the results from other studies of cellulose-PP composites [13,14]. Table 3 shows the values of $\%$ crystallinity calculated from DSC curves of the first heating scan of the composites according to Eq. (1) and crystallization temperature. The crystallization temperatures of vetiver-PP composites slightly increase with increasing vetiver content. This may indicate the nucleating effect from vetiver fiber in the composite. However, crystallinity is insignificantly changed with increasing vetiver content. This may be due to the vetiver fibers which may act into two opposite ways. Generally, the crystallization process is governed by nucleation and crystal growth. The vetiver fiber acts as a nucleating agent in the nucleation step. This should result in increasing crystallization temperature and crystallinity. However, after nucleation, the presence of vetiver fiber may restrict the molecular mobility in the melt of PP matrix leading to the lower crystallinity. This causes the insignificant change in crystallinity with increasing vetiver content. 

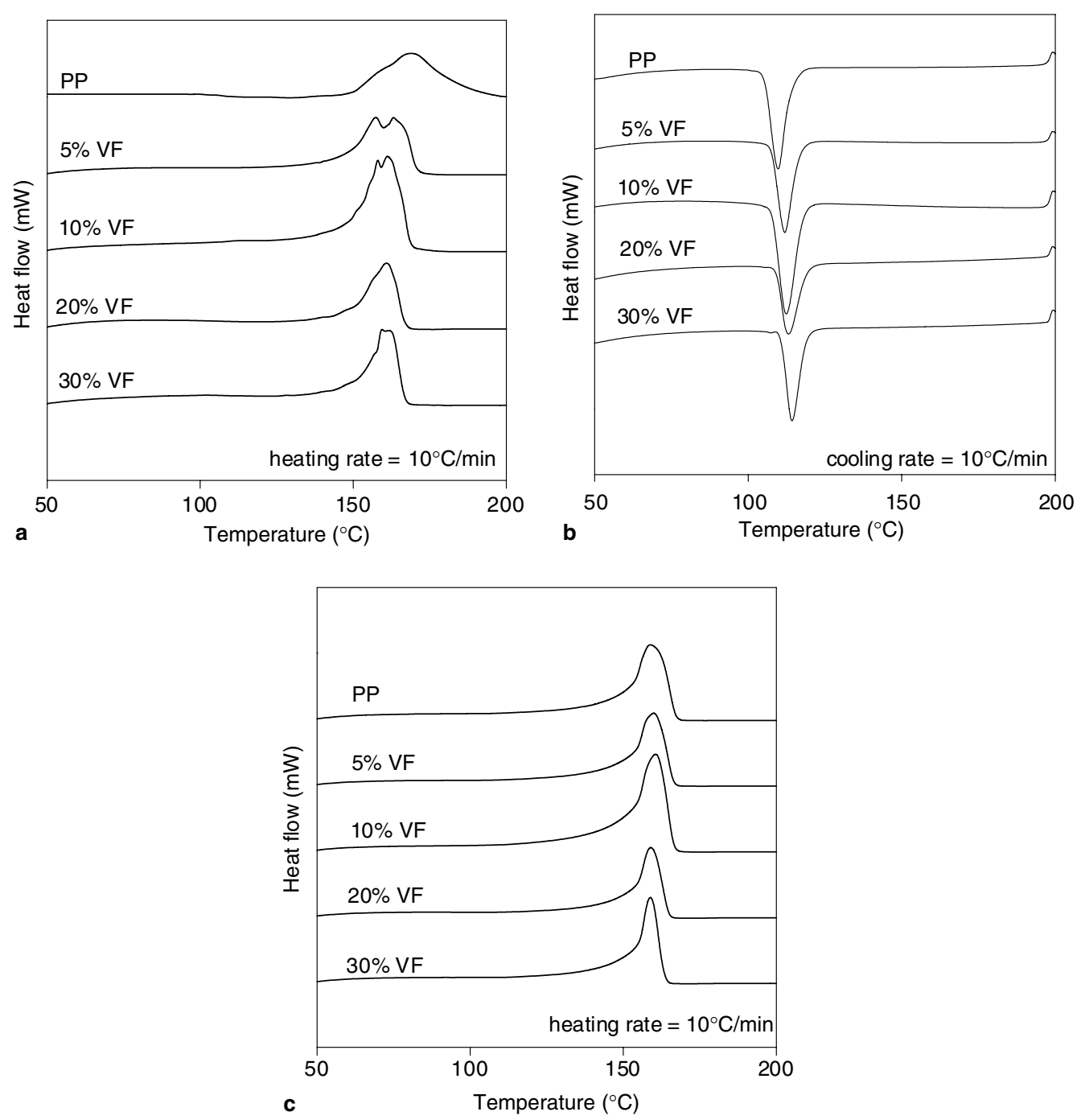

Fig. 3. DSC curves corresponding to (a) the first heating scan, (b) the cooling scan and (c) the second heating scan of PP and VF-PP composites at 5\%, $10 \%, 20 \%$, and $30 \%$ vetiver contents.

Table 3

Crystallization temperature and \% crystallinity of vetiver-PP composites from $\mathrm{VF}$ at various vetiver contents

\begin{tabular}{lll}
\hline $\begin{array}{l}\text { Vetiver } \\
\text { content (wt.\%) }\end{array}$ & $\begin{array}{l}\text { Crystallization } \\
\text { temperature }\left({ }^{\circ} \mathrm{C}\right)\end{array}$ & Crystallinity $(\%)$ \\
\hline 0 & 109 & 45.1 \\
5 & 111 & 47.1 \\
10 & 112 & 49.3 \\
20 & 113 & 47.3 \\
30 & 114 & 48.1 \\
\hline
\end{tabular}

\subsubsection{The effect of chemical treatment on thermal properties of vetiver-PP composites}

TGA and DTG curves of vetiver-PP composites from VL, $\mathrm{NaOH}-\mathrm{VL}, \mathrm{VF}$, and $\mathrm{NaOH}$-silane-VF at $20 \%$ vetiver content are shown in Fig. 4. The decomposition temperatures of $\alpha$-cellulose of the composites from $\mathrm{NaOH}-\mathrm{VL}, \mathrm{VF}$, and $\mathrm{NaOH}$-silane- $\mathrm{VF}$ are in the same range $\left(351-353^{\circ} \mathrm{C}\right.$ ), which are higher than those of $\mathrm{NaOH}-\mathrm{VL}, \mathrm{VF}$, and
$\mathrm{NaOH}$-silane-VF $\left(343-348^{\circ} \mathrm{C}\right)$. Nevertheless, the decomposition of $\alpha$-cellulose of the composite from VL is not observed as a peak in the DTG curve. However, the beginning decomposition temperature of the composite from $\mathrm{VL}$ is lower than those of the composites from $\mathrm{NaOH}-\mathrm{VL}$, $\mathrm{VF}$, and $\mathrm{NaOH}$-silane-VF. This is due to the lower thermal stability of VL.

DSC curves of PP composites from VL, NaOH-VL, VF, and $\mathrm{NaOH}$-silane-VF at $20 \%$ vetiver content obtained from the first heating scan, the cooling scan, and the second heating scan are shown in Fig. 5(a)-(c), respectively. The first heating curves show several small melting peaks, which may indicate various forms of crystal formed during processing. These different forms of crystal disappear after removing the thermal history as shown by the single melting peak in the second heating scans. From Fig. 5(a), there is no significant change in melting temperature among the composites from VL, NaOH-VL, VF, and $\mathrm{NaOH}$-silaneVF. The $\%$ crystallinity and crystallization temperature 


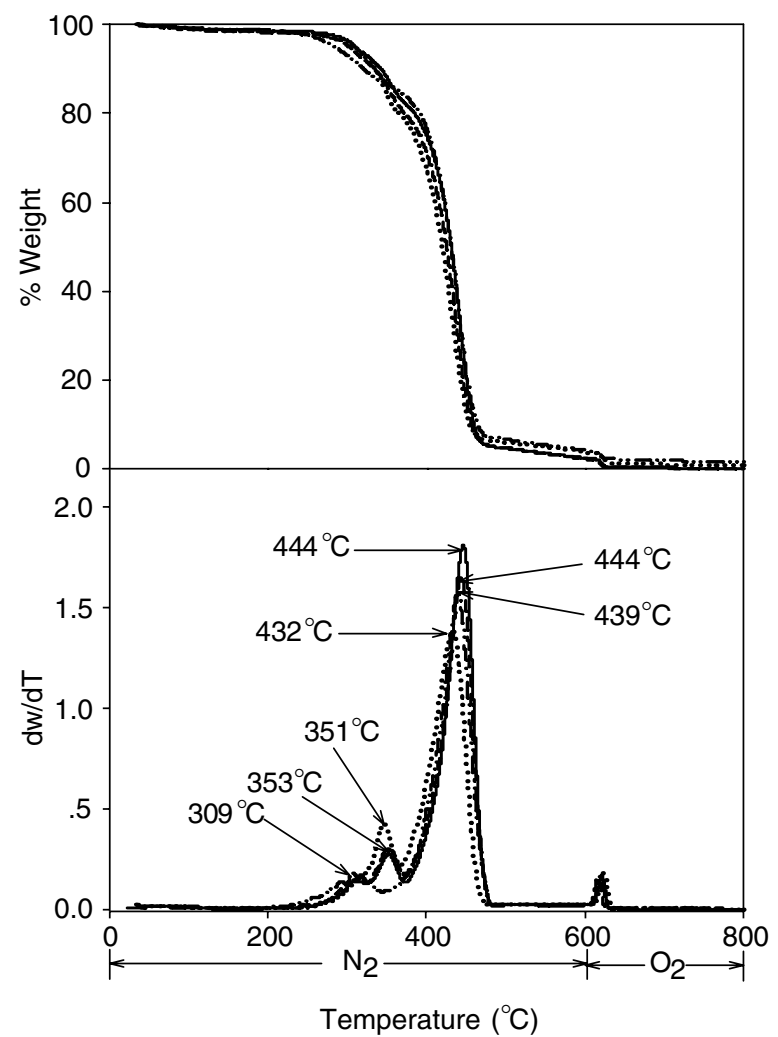

Fig. 4. TGA and DTG curves of vetiver-PP composites from VL, NaOH$\mathrm{VL}, \mathrm{VF}$, and $\mathrm{NaOH}$-silane- $\mathrm{VF}$ at $20 \%$ vetiver content.

are shown in Table 4. Crystallization temperature and \% crystallinity of the composites from VL, NaOH-VL, VF, and $\mathrm{NaOH}$-silane-VF show no significant difference.

\subsection{Rheological properties of vetiver-PP composites}

\subsubsection{The effect of vetiver content on rheological properties of vetiver-PP composites}

MFI of PP and vetiver-PP composites from VF at various vetiver contents are shown in Table 5. MFI of PP is higher than that of PP composites. With increasing vetiver content, the MFI of the composites decreases. This indicates that viscosity of the composites increases with increasing vetiver content.

Flow curves of PP composites from $\mathrm{VL}, \mathrm{NaOH}-\mathrm{VL}$, and $\mathrm{VF}$ at various vetiver contents are shown in Fig. 6(a)-(c), respectively. The vetiver-PP composites exhibit higher viscosity than that of PP. This is because the vetiver grass perturbs the flow of polymer and hinders the mobility of chain segments in melt flow. In addition, the viscosity of the vetiver-PP composites increases with increasing vetiver content. An increase in viscosity of the composites with increasing vetiver content is more predominant at low shear rate $\left(10-10^{2} \mathrm{~s}^{-1}\right)$ than that of at high shear rates $\left(10^{2}-10^{4} \mathrm{~s}^{-1}\right)$. An increase in viscosity of the composites with increasing fiber contents is also found from the study of natural fiber composites $[15,16]$. It is interesting to point out that the viscosity at high shear rates $\left(10^{2}-10^{4} \mathrm{~s}^{-1}\right)$ of
vetiver-PP composites at $20 \%$ vetiver content is about 1.2 times higher than that of PP. This is similar to the viscosity of glass fiber-PP composite at the same shear rate and fiber content which is about 1.1 times higher than that of PP [17].

\subsubsection{The effect of chemical treatment on rheological properties of vetiver-PP composites}

MFI of vetiver-PP composites from VL, NaOH-VL, $\mathrm{VF}$, and $\mathrm{NaOH}$-silane-VF at $20 \%$ vetiver content are shown in Table 6 . The vetiver-PP composites from vetiver fibers (VF and $\mathrm{NaOH}$-silane-VF) show slightly lower MFI than those of vetiver-PP composites from vetiver leaves ( $\mathrm{VL}$ and $\mathrm{NaOH}-\mathrm{VL}$ ). This means that the viscosity of vetiver-PP composites from vetiver fiber is higher than those of vetiver leaves. This is also shown in the flow curves of vetiver-PP composites from VL, NaOH-VL, VF, and $\mathrm{NaOH}$-silane-VF at $20 \%$ vetiver content (Fig. 7). At high shear rate $\left(10^{2}-10^{4} \mathrm{~s}^{-1}\right)$, the viscosity of PP composites from VL, $\mathrm{NaOH}-\mathrm{VL}, \mathrm{VF}$, and $\mathrm{NaOH}$-silane-VF shows no difference.

\subsection{Mechanical properties of vetiver-PP composites}

\subsubsection{The effect of mixing procedures on mechanical properties of vetiver-PP composites}

The effect of mixing procedures on mechanical properties of $20 \%$ vetiver-PP composites with the length of $2 \mathrm{~mm}$, method A and B, are shown in Table 7. The differences of the two methods are the sequence of adding $\mathrm{NaOH}-\mathrm{VL}$ in the composites and the mixing time after adding $\mathrm{NaOH}-\mathrm{VL}$. In method $\mathrm{A}, \mathrm{NaOH}-\mathrm{VL}$ was added after melting PP for 5 min and the mixing time after adding $\mathrm{NaOH}-\mathrm{VL}$ was $5 \mathrm{~min}$. In method $\mathrm{B}, \mathrm{NaOH}-\mathrm{VL}$ and $\mathrm{PP}$ were mixed together for $10 \mathrm{~min}$. The tensile strength and impact strength of the composites from method $\mathrm{A}$ and method B show no significant difference. Nevertheless, Young's modulus of the composites from method B is higher than that of the composites from method A. However, the elongation at break from method B is lower than that of the composites from method $\mathrm{A}$. This can be explained as follow; the longer mixing time of $\mathrm{NaOH}-\mathrm{VL}$ in the composites leads to the better dispersion of vetiver in PP matrix. On the other hands, the longer mixing time may cause the degradation of the vetiver due to the low thermal resistance of the vetiver.

\subsubsection{The effect of vetiver length on mechanical properties of vetiver-PP composites}

The effect of vetiver length on tensile strength, Young's modulus, elongation at break, and impact strength of vetiver-PP composites from $\mathrm{NaOH}-\mathrm{VL}$ at $20 \%$ vetiver content are shown in Table 8 . The vetiver-PP composites at various vetiver lengths show no difference in tensile strength and Young's modulus. Elongation at break of the composites slightly decreases at vetiver length of $4 \mathrm{~mm}$. With increasing vetiver length, a decrease in impact strength of the 

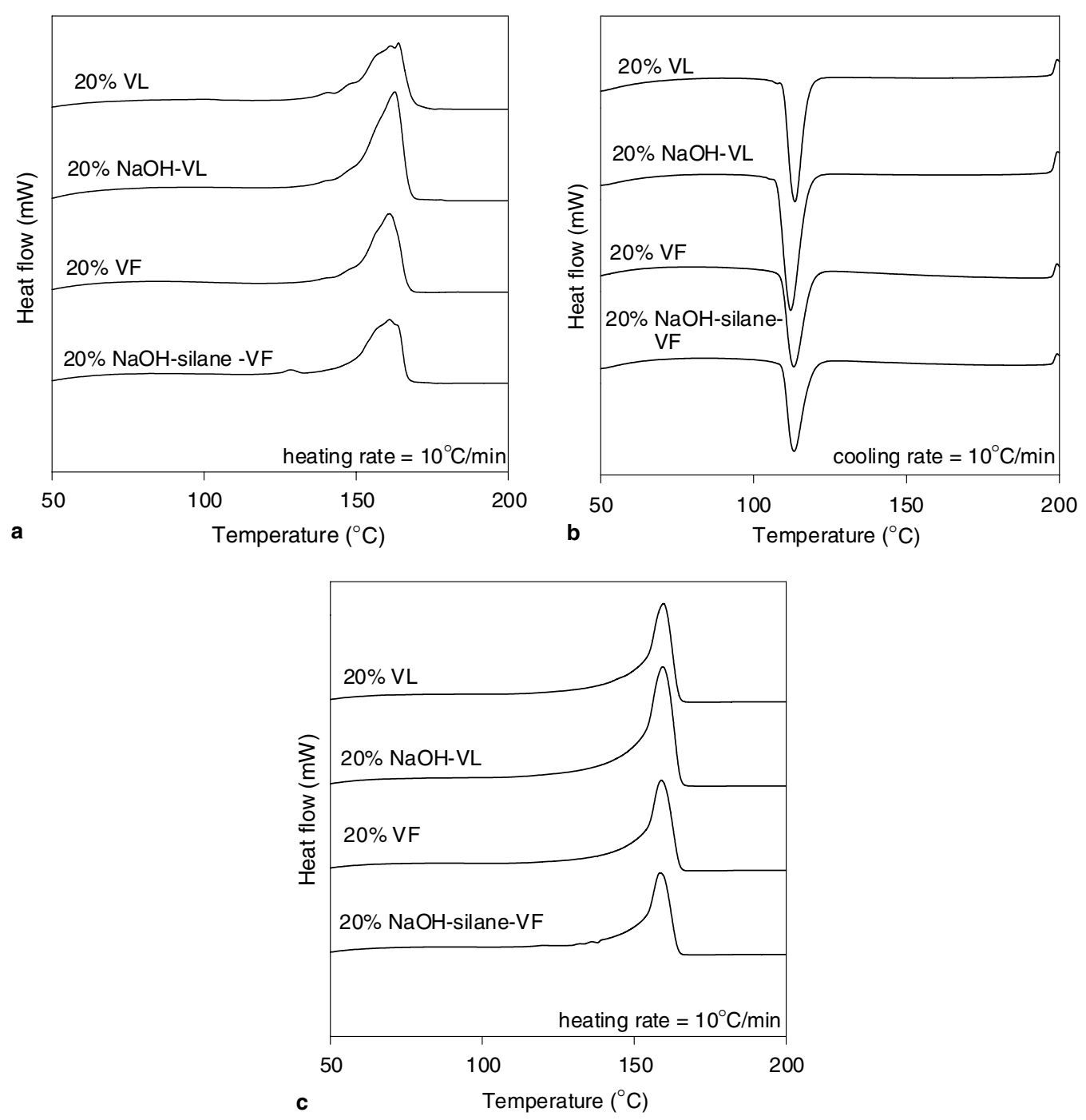

Fig. 5. DSC curves corresponding to (a) the first heating scan, (b) the cooling scan and (c) the second heating scan of vetiver-PP composites from VL, $\mathrm{NaOH}-\mathrm{VL}, \mathrm{VF}$, and $\mathrm{NaOH}$-silane-VF at $20 \%$ vetiver content.

Table 4

Crystallization temperature and \% crystallinity of vetiver-PP composites from $\mathrm{VL}, \mathrm{NaOH}-\mathrm{VL}, \mathrm{VF}$, and $\mathrm{NaOH}$-silane-VF at $20 \%$ vetiver content

\begin{tabular}{lll}
\hline $\begin{array}{l}\text { Types of } \\
\text { vetiver grass }\end{array}$ & $\begin{array}{l}\text { Crystallization } \\
\text { temperature }\left({ }^{\circ} \mathrm{C}\right)\end{array}$ & Crystallinity $(\%)$ \\
\hline $\mathrm{VL}$ & 113 & 47.1 \\
$\mathrm{NaOH}-\mathrm{VL}$ & 112 & 48.4 \\
$\mathrm{VF}$ & 113 & 47.3 \\
$\mathrm{NaOH}-$ silane-VF & 113 & 50.8 \\
\hline
\end{tabular}

Table 5

MFI of PP and vetiver-PP composites from VF at various vetiver contents

\begin{tabular}{ll}
\hline Vetiver content (wt.\%) & MFI (g/10 min) \\
\hline 0 & 3.02 \\
5 & 2.83 \\
10 & 2.09 \\
20 & 1.17 \\
30 & 0.65 \\
\hline
\end{tabular}

composites is observed. During the processing of the composites, some vetiver grass at longer vetiver lengths may be broken into shorter length. The final length of $\mathrm{NaOH}-\mathrm{VL}$ in the composites prepared from various vetiver lengths may not be much different. This may cause no significant change in mechanical properties of the composites. Similarly, a study of flax-PP composite and sisal-PP composite have shown that tensile strength of the composites does not change when fiber length is longer than $5 \mathrm{~mm}[18,19]$.

\subsubsection{The effect of vetiver content on mechanical properties of vetiver-PP composites}

The effect of vetiver content on tensile strength, Young's modulus, elongation at break, and impact strength of vetiver-PP composites from $\mathrm{NaOH}-\mathrm{VL}$ at various vetiver contents are given in Table 9. It can be observed that the tensile strength of vetiver-PP composites is higher than that of PP. This is because the tensile strength of vetiver grass, according to Table 1 (247-723 MPa), is much higher than that of PP (12.58 MPa). Nevertheless, with increasing 

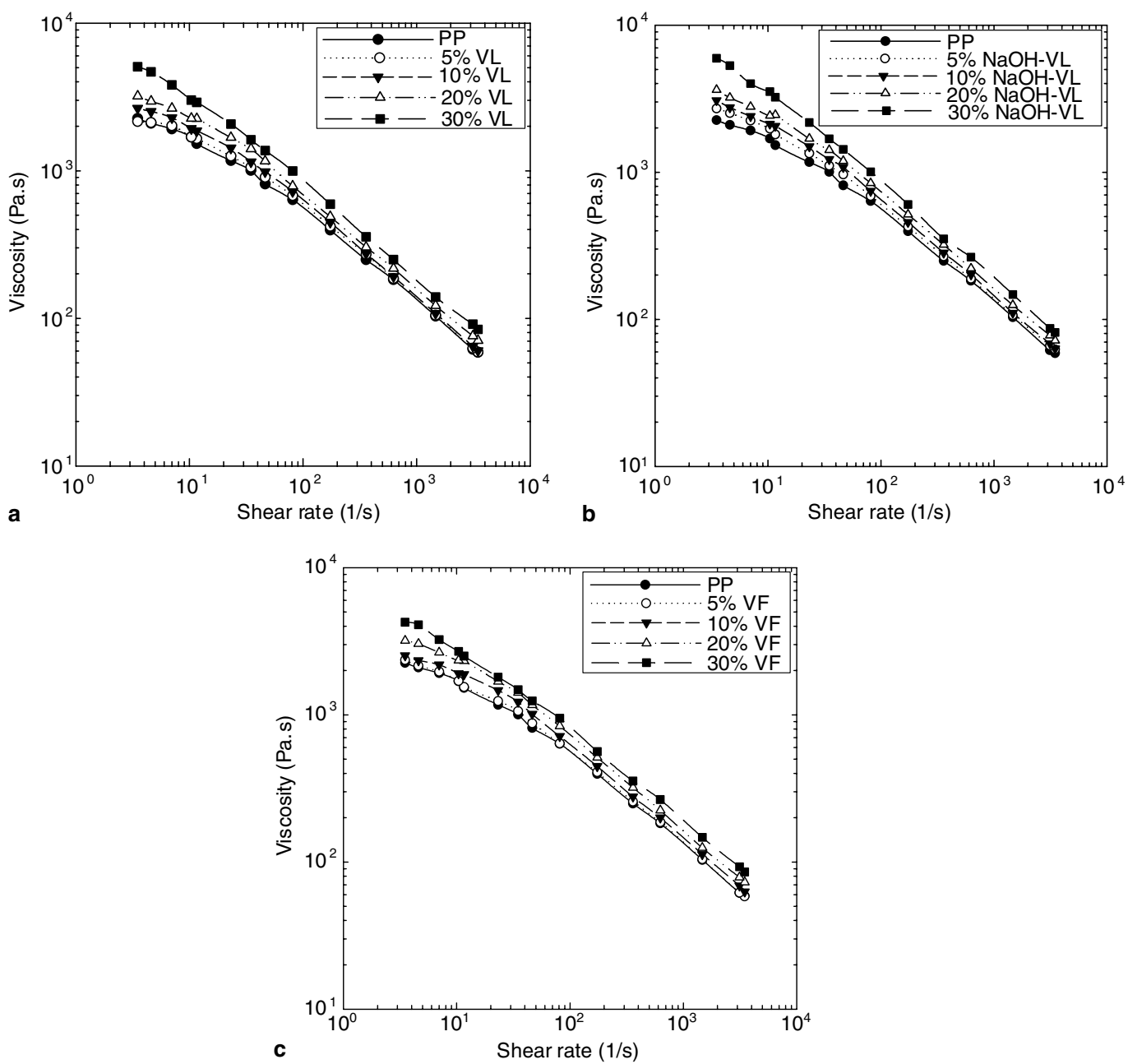

Fig. 6. Flow curves of PP and vetiver-PP composites from (a) VL, (b) NaOH-VL and (c) VF at various vetiver contents.

Table 6

MFI of vetiver-PP composites from VL, $\mathrm{NaOH}-\mathrm{VL}, \mathrm{VF}$, and $\mathrm{NaOH}$-silaneVF at $20 \%$ vetiver content

\begin{tabular}{ll}
\hline Types of vetiver grass & MFI $(\mathrm{g} / 10 \mathrm{~min})$ \\
\hline $\mathrm{VL}$ & 1.66 \\
$\mathrm{NaOH}-\mathrm{VL}$ & 1.36 \\
$\mathrm{VF}$ & 1.17 \\
$\mathrm{NaOH}-$ silane-VF & 1.17 \\
\hline
\end{tabular}

vetiver content, the tensile strength of the composites slightly decreases. This is because the polar surface of VL is not compatible to the nonpolar PP matrix. Therefore the increase of vetiver content facilitates more slippage of fiber from PP matrix. Also, the reduction of the tensile strength of the composites at higher vetiver content is attributed to an increase in number of void in the composites, which is served as a local area for crack initiation. A decrease in tensile strength with increasing fiber content has also been observed in the PP composites from kudzu, conifer, and sisal fiber [15,20-22]. In contrast, the study of sisal-PP composites has shown an increase in tensile strength with increasing fiber content [23]. However, no

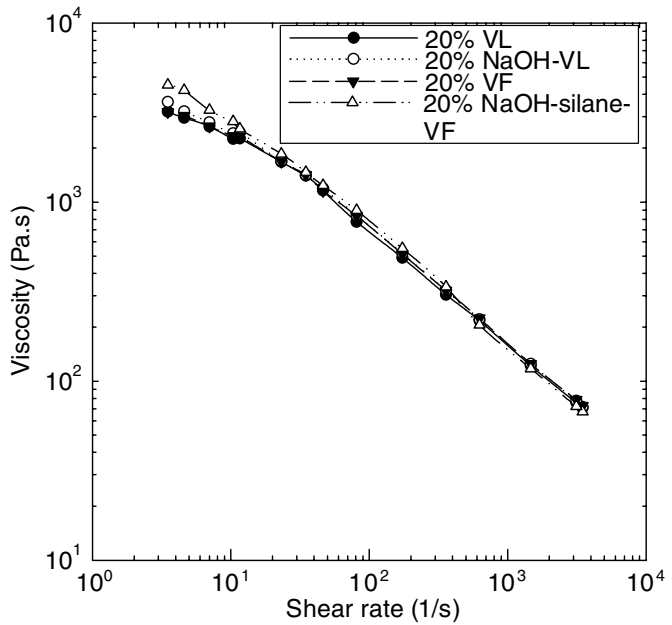

Fig. 7. Flow curves of vetiver-PP composites from VL, NaOH-VL, VF, and $\mathrm{NaOH}$-silane-VF at $20 \%$ vetiver content.

significant change in tensile strength with increasing fiber content has been found in the study of kenaf-PP composite [24]. 
Table 7

Tensile strength, Young's modulus, elongation at break, and impact strength of $20 \%$ vetiver-PP composites from NaOH-VL with vetiver length of $2 \mathrm{~mm}$ by different mixing procedures

\begin{tabular}{lllll}
\hline Methods & $\begin{array}{l}\text { Tensile } \\
\text { strength } \\
(\mathrm{MPa})\end{array}$ & $\begin{array}{l}\text { Young's } \\
\text { modulus } \\
(\mathrm{MPa})\end{array}$ & $\begin{array}{l}\text { Elongation } \\
\text { at break } \\
(\%)\end{array}$ & $\begin{array}{l}\text { Impact } \\
\text { strength } \\
\left(\mathrm{kJ} / \mathrm{m}^{2}\right)\end{array}$ \\
\hline $\mathrm{A}$ & $26.08 \pm 0.69$ & $548.18 \pm 49.17$ & $11.33 \pm 0.77$ & $18.97 \pm 1.51$ \\
$\mathrm{~B}$ & $25.73 \pm 0.26$ & $1220.00 \pm 50.35$ & $7.90 \pm 0.70$ & $17.25 \pm 0.95$
\end{tabular}

Table 8

Tensile strength, Young's modulus, elongation at break, and impact strength of vetiver-PP composites from NaOH-VL (prepared by Method A) at $20 \%$ vetiver content

\begin{tabular}{lllll}
\hline $\begin{array}{l}\text { Vetiver } \\
\text { lengths } \\
(\mathrm{mm})\end{array}$ & $\begin{array}{l}\text { Tensile } \\
\text { strength } \\
(\mathrm{MPa})\end{array}$ & $\begin{array}{l}\text { Young's } \\
\text { modulus } \\
(\mathrm{MPa})\end{array}$ & $\begin{array}{l}\text { Elongation } \\
\text { at break } \\
(\%)\end{array}$ & $\begin{array}{l}\text { Impact } \\
\text { strength } \\
\left(\mathrm{kJ} / \mathrm{m}^{2}\right)\end{array}$ \\
\hline 0.1 & $24.93 \pm 0.86$ & $592.45 \pm 36.19$ & $11.30 \pm 0.54$ & $20.32 \pm 1.15$ \\
2 & $26.08 \pm 0.69$ & $548.18 \pm 49.17$ & $11.33 \pm 0.77$ & $18.97 \pm 1.51$ \\
4 & $25.92 \pm 0.40$ & $573.30 \pm 27.65$ & $9.19 \pm 0.33$ & $15.62 \pm 2.19$ \\
\hline
\end{tabular}

Elongation at break of vetiver-PP composites decreases with increasing vetiver content. This is because vetiver grass has lower elongation at break than that of PP. A decrease in elongation at break with increasing fiber content was also observed in other studies of natural fiber composites $[15,21,25]$.

The impact strength of PP cannot be obtained because it does not break within the limit of the instrument (maximum energy of $5.4 \mathrm{~J}$ ). However, this implies that the impact strength of vetiver-PP composites is lower than that of PP. The impact strength of the composites decreases with increasing vetiver content. The higher amount of $\mathrm{NaOH}-$ $\mathrm{VL}$ also increases a probability of $\mathrm{NaOH}-\mathrm{VL}$ agglomeration and creates void in the composites. This leads to poor adhesion between vetiver and PP matrix and causes more crack initiation, which leads to the composite failure. As a result, the impact strength decreases with increasing vetiver content. Other studies of the natural fiber-PP composite $[23,26]$ have also reported a decrease in impact strength of composites with increasing fiber content.

Young's modulus of vetiver-PP composites increases with increasing vetiver content. This is because the Young's modulus of vetiver grass according to Table $1(23.2 \mathrm{GPa})$ is much higher than that of PP $(0.8 \mathrm{GPa})$. This results in the increase of Young's modulus of the composites. An increase in Young's modulus of the composites with increasing fiber content has also been observed in other natural fibers-PP composites [5,18,19,21,24].

HDT of PP and vetiver-PP composites from VF at various vetiver contents are shown in Table 10. The HDT of vetiver-PP composites increases with increasing vetiver content. At vetiver content of $30 \%$, the HDT of the composites increases up to $64 \%$ compared to that of PP. From the study of conifer-PP composites, the HDT of the composites increases about $2 \%$ compared to that of PP [15].

\subsubsection{The effect of chemical treatment on mechanical properties of vetiver-PP composites}

The tensile strength, Young's modulus, elongation at break, and impact strength of vetiver-PP composites from $\mathrm{VL}, \mathrm{NaOH}-\mathrm{VL}, \mathrm{VF}$, and $\mathrm{NaOH}$-silane-VF are given in Table 11. The tensile strength, Young's modulus, elongation at break, and impact strength of vetiver-PP composites from $\mathrm{NaOH}-\mathrm{VL}$ are slightly higher than that of vetiver-PP composites from VL. In addition, tensile strength, Young's modulus, elongation at break, and impact strength of vetiver-PP composites from $\mathrm{NaOH}$-silane-VF are slightly higher than that of the composites from VF. The reason why $\mathrm{NaOH}$ treatment improves the mechanical properties of the composites will be discussed along with the morphology of the composites in next section. Similarly, several authors have reported that the silane treatment improves the mechanical properties of natural fiber-PP composite $[18,23,27]$.

HDT of vetiver-PP composites from VL, NaOH-VL, $\mathrm{VF}$, and $\mathrm{NaOH}$-silane-VF at $20 \%$ vetiver content are shown in Table 12. It shows no significant difference in HDT of vetiver-PP composites from VL, NaOH-VL, VF, and $\mathrm{NaOH}$-silane-VF.

Table 10

HDT of PP and vetiver-PP composites from VF (prepared by Method B) at various vetiver contents

\begin{tabular}{lc}
\hline Vetiver content (wt.\%) & HDT $\left({ }^{\circ} \mathrm{C}\right)$ \\
\hline 0 & $81 \pm 1.0$ \\
5 & $94 \pm 0.5$ \\
10 & $109 \pm 1.0$ \\
20 & $125 \pm 0.0$ \\
30 & $133 \pm 1.0$ \\
\hline
\end{tabular}

Table 9

Tensile strength, Young's modulus, elongation at break, and impact strength of vetiver-PP composites from NaOH-VL (prepared by Method B) at vetiver length of $2 \mathrm{~mm}$

\begin{tabular}{llccc}
\hline Vetiver content $($ wt.\%) & Tensile strength $(\mathrm{MPa})$ & Young's modulus $(\mathrm{MPa})$ & Elongation at break $(\%)$ & Impact strength $\left(\mathrm{kJ} / \mathrm{m}^{2}\right)$ \\
\hline 0 & $12.58 \pm 0.45^{\mathrm{a}}$ & $732.45 \pm 14.13^{\mathrm{a}}$ & $94.25 \pm 0.70^{\mathrm{a}}$ & $>119.60$ \\
5 & $27.08 \pm 0.26$ & $809.52 \pm 42.48$ & $16.63 \pm 1.02$ & $30.66 \pm 3.34$ \\
10 & $26.60 \pm 0.59$ & $925.83 \pm 47.36$ & $12.44 \pm 0.93$ & $21.43 \pm 1.12$ \\
20 & $25.73 \pm 0.26$ & $1220.00 \pm 50.35$ & $7.90 \pm 0.70$ & $17.25 \pm 0.95$ \\
30 & $25.12 \pm 0.59$ & $1565.00 \pm 44.22$ & $6.12 \pm 0.47$ & $16.65 \pm 1.09$
\end{tabular}

${ }^{\text {a }}$ Test speed $50 \mathrm{~mm} / \mathrm{min}$. 
Table 11

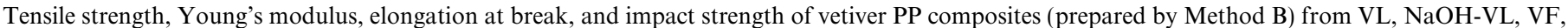
and $\mathrm{NaOH}$-silane- VF at $20 \%$ vetiver content

\begin{tabular}{|c|c|c|c|c|}
\hline Types of vetiver grass & Tensile strength $(\mathrm{MPa})$ & Young's modulus (MPa) & Elongation at break $(\%)$ & Impact strength $\left(\mathrm{kJ} / \mathrm{m}^{2}\right)$ \\
\hline VL & $25.14 \pm 0.41$ & $1196.98 \pm 41.13$ & $7.27 \pm 0.67$ & $15.79 \pm 0.32$ \\
\hline $\mathrm{NaOH}-\mathrm{VL}$ & $25.73 \pm 0.26$ & $1220.00 \pm 50.35$ & $7.90 \pm 0.70$ & $17.25 \pm 0.95$ \\
\hline VF & $24.32 \pm 0.46$ & $954.33 \pm 38.13$ & $8.17 \pm 0.40$ & $17.14 \pm 0.83$ \\
\hline $\mathrm{NaOH}$-silane-VF & $24.53 \pm 0.14$ & $1051.93 \pm 29.34$ & $9.30 \pm 0.70$ & $20.44 \pm 0.53$ \\
\hline
\end{tabular}

3.5. Morphological properties of vetiver grass and vetiverPP composites

\subsubsection{The effect of chemical treatment on morphological properties of vetiver grass}

The SEM micrographs of VL, NaOH-VL, VF, and $\mathrm{NaOH}$-silane-VF, are shown in Fig. 8(a)-(d), respectively. These micrographs reveal the effect of $\mathrm{NaOH}$ treatment on the microstructure of $\mathrm{NaOH}-\mathrm{VL}$ and $\mathrm{NaOH}$-silaneVF. The treatment results in the removal of some impurities. In addition, $\mathrm{NaOH}$ treatment breaks down the composite fiber bundle into smaller fibers. These increase the effective surface area available for contact between $\mathrm{NaOH}-\mathrm{VL}$ and PP matrix. Also in the case of $\mathrm{NaOH}-$

Table 12

HDT of vetiver-PP composites (prepared by Method B) from VL, NaOH$\mathrm{VL}, \mathrm{VF}$, and $\mathrm{NaOH}$-silane-VF at $20 \%$ vetiver content

\begin{tabular}{ll}
\hline Types of vetiver grass & HDT $\left({ }^{\circ} \mathrm{C}\right)$ \\
\hline $\mathrm{VL}$ & $123 \pm 0.6$ \\
$\mathrm{NaOH}-\mathrm{VL}$ & $124 \pm 0.6$ \\
$\mathrm{VF}$ & $125 \pm 0.0$ \\
$\mathrm{NaOH}-$ silane-VF & $125 \pm 0.6$ \\
\hline
\end{tabular}

silane-VF, the $\mathrm{NaOH}$ treatment improves the deposition of silane onto the fibers. This may cause more physical or chemical bonding between $\mathrm{NaOH}$-silane-VF and $\mathrm{PP}$ matrix. Therefore, the $\mathrm{NaOH}$ treatment results in the better mechanical properties of the composites from $\mathrm{NaOH}-$ $\mathrm{VL}$ and $\mathrm{NaOH}$-silane-VF. Similarly, many researchers have reported that $\mathrm{NaOH}$ treatment on jute, sisal, hemp, and oil palm fibers can partially remove the hemicellulose, waxes and lignin presenting on the surface of fiber [28-34].

\subsubsection{The effect of vetiver content on morphological properties of vetiver-PP composites}

SEM micrographs of fracture surfaces of PP composites from VF at various vetiver contents are shown in Fig. 9. With increasing vetiver content, SEM micrographs show more agglomeration of vetiver fiber. This results in lower tensile strength and lower impact strength of the composites.

\subsection{Weathering resistance of vetiver-PP composites}

The effect of weathering resistance on tensile strength, Young's modulus, elongation at break, and impact strength

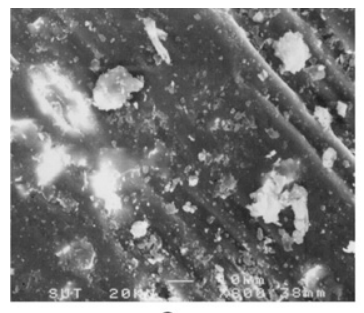

a

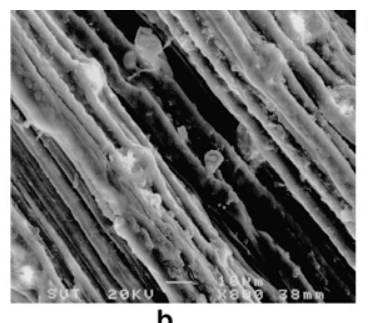

b

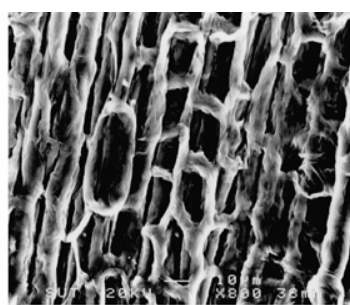

C

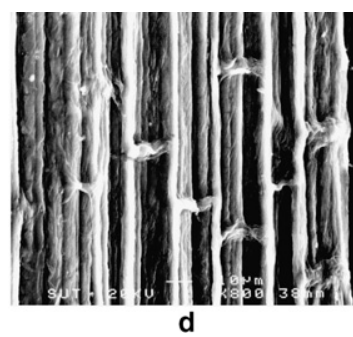

Fig. 8. SEM micrographs of vetiver grass: (a) VL, (b) NaOH-VL, (c) VF and (d) NaOH-silane- VF.

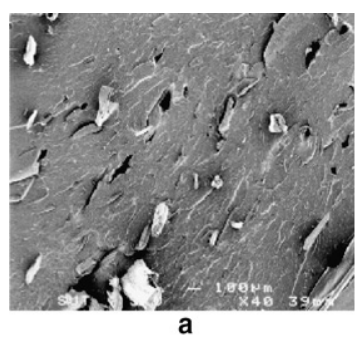

a

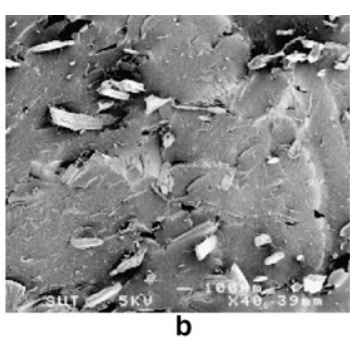

b
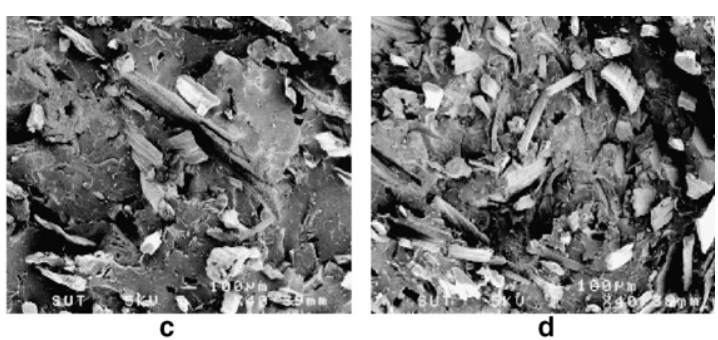

Fig. 9. SEM micrographs of fracture surfaces of vetiver-PP composites from VF at various vetiver contents (a) $5 \%$, (b) $10 \%$, (c) $20 \%$ and (d) $30 \%$. 
Table 13

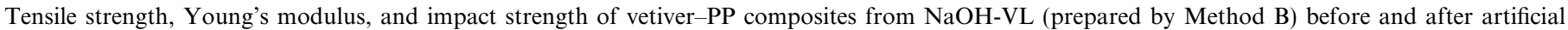
weathering test at various vetiver contents

\begin{tabular}{|c|c|c|c|c|c|c|}
\hline \multirow[t]{2}{*}{ Vetiver content (wt.\%) } & \multicolumn{2}{|c|}{ Tensile strength $(\mathrm{MPa})$} & \multicolumn{2}{|c|}{ Young's modulus (MPa) } & \multicolumn{2}{|c|}{ Impact strength $\left(\mathrm{kJ} / \mathrm{m}^{2}\right)$} \\
\hline & Before & After & Before & After & Before & After \\
\hline 0 & $12.58 \pm 0.45^{*}$ & $18.06 \pm 0.59^{*}$ & $732.45 \pm 14.13^{*}$ & $685.14 \pm 6.80^{*}$ & $>119.60$ & $>119.60$ \\
\hline 10 & $26.60 \pm 0.59$ & $25.48 \pm 0.62$ & $925.83 \pm 47.36$ & $783.28 \pm 45.22$ & $21.43 \pm 1.12$ & $8.45 \pm 0.93$ \\
\hline 20 & $25.73 \pm 0.26$ & $24.03 \pm 0.49$ & $1220.00 \pm 50.35$ & $861.36 \pm 47.63$ & $17.25 \pm 0.95$ & $8.19 \pm 0.89$ \\
\hline 30 & $25.12 \pm 0.59$ & $21.83 \pm 0.37$ & $1565.00 \pm 44.22$ & $1016.84 \pm 29.78$ & $16.65 \pm 1.09$ & $10.12 \pm 1.06$ \\
\hline
\end{tabular}

Test speed is $50 \mathrm{~mm} / \mathrm{min}$.

of vetiver-PP composites from $\mathrm{NaOH}-\mathrm{VL}$ at various vetiver contents are given in Table 13. After artificial weathering test, the tensile strength of vetiver-PP composites slightly decreases. Moreover, Young's modulus of vetiver-PP composites decreases from about $10 \%$ to $35 \%$ when the vetiver content increases from $10 \%$ to $30 \%$. The impact strength of vetiver-PP composites approximately decreases to $60 \%, 52 \%$, and $39 \%$ when the vetiver content increases from $10 \%$ to $30 \%$. An increase in tensile strength of PP is observed after the weathering test. This may be due to the crosslink of PP during the test.

\section{Conclusions}

The decomposition temperature of vetiver-PP composites decreases with increasing vetiver content. In addition, the decomposition temperature of $\alpha$-cellulose of the composites is higher than that of vetiver grass. The vetiver-PP composites with increasing vetiver content show no significant change in melting temperature. The crystallization temperature of vetiver-PP composites increases with increasing vetiver content. The melt temperature of the vetiver-PP composite from VL, NaOH-VL, VF, and $\mathrm{NaOH}$-silaneVF showes no significant difference. The crystallization temperature and \% crystallinity of vetiver-PP composite from $\mathrm{VL}, \mathrm{NaOH}-\mathrm{VL}, \mathrm{VF}$, and $\mathrm{NaOH}$-silane-VF show no difference as well.

The vetiver-PP composites at various vetiver lengths show no significant change in mechanical properties of the composites. Compared to PP, vetiver-PP composites show higher tensile strength and Young's modulus but lower elongation at break and impact strength. With increasing vetiver content, tensile strength, elongation at break, and impact strength of vetiver-PP composites slightly decrease while Young's modulus increases. Moreover, HDT of vetiver-PP composites increases with increasing vetiver content. In addition, the chemical treatment improves the mechanical properties of the composites.

\section{Acknowledgements}

The authors would like to thank Suranaree University of Technology for financial supports to this project, and The Land Development Department, Nakhon Ratchasima for supplying the vetiver grass.

\section{References}

[1] Bledzki AK, Gassan J. Composites reinforced with cellulose based fibres. Prog Polym Sci 1999;24:221-74.

[2] Schuh TG. Renewable Materials for Automotive Applications. Available from: $<$ http://www.ienica.net/fibresseminar/schuh.pdf $>$.

[3] Bruijn JCM. Natural fibre mat thermoplastic products from a processor's point of view. Appl Comp Mater 2000;7:415-20.

[4] Saheb DN, Jog JP. Natural fiber polymer composites: a review. Adv Polym Technol 1999;18:351-63.

[5] Wambua P, Iens J, Verpoest I. Natural fibres: can they replace glass in fibre reinforced plastics. Comp Sci Technol 2003;63:1259-64.

[6] Mohanty AK, Misra M, Hinrichsen G. Biofibres, biodegradale polymers and biocomposites: an overview. Macromol Mater Eng 2000;276/277:1-24.

[7] Nakorn WN, Chinapan W, Tepnanraprapai P. Factual tips about vetiver grass. Bangkok: Text and journal; 1999.

[8] Krevelen DW. Properties of polymer. New York: Elsevier Science; 1997.

[9] Ray D, Sakar BK, Basak RK, Rana AK. Study of the thermal behavior of alkali treated jute fibers. J Appl Polym Sci 2002;85:2594-9.

[10] Albano C, Gonzalez J, Ichazo M, Kaiser D. Thermal stability of blend of polyolefins and sisal fiber. Polym Degrad Stability 1999;66:179-90.

[11] Joseph PV, Joseph K, Thomas S, Pillai CKS, Prasad VS, Groeninckx $\mathrm{G}$, et al. The thermal properties and crystallisation studies of short sisal fibre reinforced polypropylene composites. Comp Part A 2003;34:253-66.

[12] Zafeiropoulos NE, Baillie CA, Matthews FL. A study of transcrystallinity and its effect on the interface in flax fibre reinforced composite materials. Comp Part A 2001;32:525-43.

[13] Amash A, Zugenmaier P. Morphology and properties of isotropic and oriented samples of cellulose fibre-polypropylene composites. Polymer 2000;41:1589-96.

[14] Manchado MAL, Biagiotti J, Torre L, Kenny JM. Effects of reinforcing fibers on the crystallization of polypropylene. Polym Eng Sci 2000;40:2194-204.

[15] Chuai C, Almdal K, Poulsen L, Plackett D. Conifer fibers as reinforcing materials for polypropylene-based composites. J Appl Polym Sci 2000;80:2833-41.

[16] George J, Janardhan R, Anand JS, Bhagawan SS, Thimas S. Melt rheological behaviour of short pineapple fiber reinforced low density polyethylene composites. Polymer 1996;37:5421-31.

[17] Thomasset J, Carreau PJ, Sanschagrin B, Ausias G. Rheological properties of long glass fiber filled polypropylene. J Non-Newtonian Fluid Mech 2005;125:25-34.

[18] Garkhail SK, HeijenRath RWH, Peijs T. Mechanical properties of natural-fiber-mat-reinforced thermoplastics based on flax fibers and polypropylene. Appl Comp Mater 2000;7:351-72.

[19] Joseph PV, Joseph K, Thomas S. Effect of processing variables on the mechanical properties of sisal-fiber-reinforced polypropylene composites. Comp Sci Technol 1999;9:1625-40. 
[20] Luo X, Benson RS, Kit KM, Dever M. Kudzu fiber reinforced polypropylene composite. J Appl Polym Sci 2002;85:1961-9.

[21] Fung KL, Li RKY, Tjong SC. Interface modification on the properties of sisal fiber-reinforced polypropylene composites. J Appl Polym Sci 2002;85:169-76.

[22] Liao B, Hunag Y, Cong G. Influence of modified wood fibers on the mechanical properties of wood fiber-reinforced polyethylene. J Appl Polym Sci 1997;66:1561-8.

[23] Joseph K, Thomas S, Pavithran C. Effect of chemical treatment on the tensile properties of short sisal fiber reinforced polyethylene composites. Polymer 1996;37:5139-49.

[24] Karnani R, Krishnan M, Naryan R. Biofiber-reinforced polypropylene composites. Polym Eng Sci 1997;37:476-83.

[25] Coutinho FMB, Costa THS, Carvalho DL. Polypropylene-wood fiber composites: effect of treatment and mixing conditions on mechanical properties. J Appl Polym Sci 1997;65:1227-35.

[26] Sanadi AR, Caulfield DF, Jacobson RE, Rowell RM. Renewable agricultural fibers as reinforcing fillers in plastics: mechanical properties of kenaf fiber polypropylene composites. Am Chem Soc 1995;34:1889-96.

[27] Valadez-Gonzalez A, Cervantes-Uc JM, Olayo R, Herrera-Franco PJ. Chemical modification of henequen fibers with an organosilane coupling agent. Comp Part B 1999;30:321-31.
[28] Sydenstricker THD, Mochnz S, Amico SC. Pull-out and other evaluations in sisal-reinforced polyester biocomposites. Polym Test 2003;22:375-80.

[29] Razera IAT, Frollini E. Composites based on jute fibers and phenolic matrices: properties of fibers and composites. J Appl Polym Sci 2004;91:1077-85.

[30] Lu X, Zhang MQ, Rong MZ, Shi G, Yang GC. Self-reinforced melt processable composites of sisal. Comp Sci Technol 2003;63:177-86.

[31] Mishra S, Misra M, Tripathy SS, Nayak SK, Mohanty AK. Graft copolymerization of acrylonitrile on chemically modified sisal fibers. Macromol Mater Eng 2001;6:107-13.

[32] George J, Sreekala MS, Thomas S. A review on interface modification and characterization of natural fiber reinforced plastic composites. Polym Eng Sci 2001;41:1471-85.

[33] Lannace S, Ali R, Nicolais L. Effect of processing conditions on dimensions of sisal fibers in thermoplastic biodegradable composites. J Appl Polym Sci 2001;79:1084-91.

[34] Mwaikambo LY, Ansell MP. The effect of chemical treatment on the properties of hemp, sisal, jute and kapok for composite reinforcement. Die Angew Makromol Chem 1999;272:108-16. 